ISSN 1518-3483

Licenciado sob uma Licença Creative Commons

\title{
Cotas raciais na universidade brasileira e a ideologia da meritocracia
}

\author{
Racial quotas in the Brazilian university and \\ the ideology of meritocracy
}

\section{Maurício Silva*}

\section{Resumo}

As ações afirmativas tornaram-se, no atual contexto brasileiro, mais do que uma mera concessão governamental no âmbito de políticas públicas universalistas, mas um imperativo inequivocamente direcionado para sanar distorções historicamente construídas em relação à população brasileira afrodescendente por meio de medidas compensatórias, Uma dessas medidas são as chamadas cotas raciais, discutidas neste artigo a partir do seu relacionamento com o ensino universitário público e da ideologia da meritocracia.

Palavras-chave: Ações afirmativas. Cotas raciais. Universidade brasileira. Meritocracia. 


\section{Abstract}

Affirmative action became, in the current Brazilian context, more than a government grant, under universalist public policies, but a activity unequivocally directed to remedy distortions historically constructed in relation to Afro-descendant Brazilian population, like compensatory measures. Some of these measures are called cotas raciais, discussed in this article from the relationship to the public university education and from the meritocractic ideology.

Keywords: Affirmative action. Cotas raciais. Brazilian university. Meritocraticy.

\section{Introdução}

Não é novidade o fato de que a precariedade da situação educacional do negro no Brasil é um algo evidente, além de cientificamente comprovado (GONÇALVES, 2003), o que levou o contingente populacional de afrodescendentes a uma drástica situação de desamparo legal, refletindo-se, sem dúvida alguma, no fato de se computar, entre essa população, um baixíssimo índice de participação no ensino básico e superior. De fato, se computarmos a situação desse contingente populacional há apenas dez anos, verificaremos que 65\% das crianças afrodescendentes viviam na pobreza (contra $38 \%$ das brancas), que $54 \%$ da população adulta de afrodescendentes ganhavam $54 \%$ menos que um branco com o mesmo grau de escolaridade e que apenas $27,4 \%$ das crianças afrodescendentes apresentavam uma taxa de conclusão do segundo ciclo do Ensino Fundamental (contra 44,3\% dos brancos) (SANTOS, 2003).

Daí o fato de as ações afirmativas tornarem-se, no atual contexto brasileiro, mais do que uma mera concessão governamental no âmbito de políticas públicas universalistas, mas um imperativo inequivocamente direcionado para sanar distorções historicamente construídas em relação 
à população brasileira afrodescendente por meio de medidas compensatórias destinadas, como demonstra Joaquim Barbosa Gomes (2005), a promover o princípio da igualdade material ou substancial, uma igualdade de resultados, em oposição à chamada igualdade formal ou procedimental, mais neutra. Com explica o mesmo autor, a fim de que se consiga inibir, de fato, a injustiça, é necessário substituir uma concepção "estática" de igualdade por uma mais "dinâmica", relacionada à ideia de que "situações desiguais sejam tratadas de maneira dessemelhante” (GOMES, 2005, p. 49), instituindo-se o que se convencionou chamar de ação afirmativa, conjunto de práticas que visam combater a discriminação de fato e transformar a sociedade com base no princípio do pluralismo e da diversidade. Assim, objetivamente, completa o autor, as ações afirmativas podem ser melhor definidas como:

um conjunto de políticas públicas e privadas de caráter compulsório, facultativo ou voluntário, concebidas com vistas ao combate à discriminação racial, de gênero, por deficiência física e de origem nacional, bem como para corrigir ou mitigar os efeitos presentes da discriminação praticada no passado, tendo como objetivo a concretização do ideal de efetiva igualdade de acesso a bens fundamentais como a educação e o emprego (GOMES, 2005, p. 55).

Mais especificamente em relação à educação, tornam-se urgentes medidas que corrijam as desigualdades de acesso e de manutenção do contingente afrodescendente nas universidades brasileiras, seja num contexto mais amplo das ações afirmativas, seja num âmbito mais restrito das cotas raciais. As cotas raciais nas universidades talvez sejam o aspecto mais saliente - e, seguramente, o mais polêmico - daqueles que estão direta ou indiretamente relacionados à questão das ações afirmativas. Pode-se dizer que, grosso modo, as cotas raciais consistem, basicamente, na reserva de parte das vagas das instituições de ensino superior para candidatos afrodescendentes, constituindo-se "numa das principais medidas afirmativas adotadas em defesa da população afro-brasileira, pois proporciona a inserção de um contingente considerável de negros na 
rede universitária do País" (MINISTÉRIO DA EDUCAÇÃO / FUNDAÇÃO CULTURAL PALMARES, 2012, s.p.). Por meio das cotas raciais, procura-se, entre outras coisas, valorizar a figura e o papel social do afrodescendente, estimulando a assunção de uma identidade que se constrói a partir da diversidade. Além disso, acreditamos que a aplicação das chamadas cotas raciais voltadas ao ensino superior desempenham papel essencial na correção das distorções acima assinaladas, congregando, de certo modo, dois princípios fundamentais: previne efeitos deletérios da discriminação, no futuro; e repara consequências de um processo histórico de discriminação, efetivado num passado não muito distante, mas ainda sistematicamente presente.

Contudo, para que se chegue à situação "ideal" no que compete à justiça social e racial no Brasil, sobretudo quando se pensa em termos de acesso à educação, em especial à educação superior, há um longo caminho a ser trilhado, o qual, a nosso ver, começa com um primeiro passo: o combate ao argumento da meritocracia.

\section{Cotas raciais e a ideologia da meritocracia}

Com efeito, a tese da igualdade por meio de mérito individual resulta de uma concepção falaciosa da dinâmica social, que tem origem no que Noëlle Bisseret chamou, muito apropriadamente, de ideologia das aptidões, responsável, entre outras coisas, pela desigualdade no acesso ao ensino, já que exprime um fato "hereditário" e "irreversível”: a superioridade natural e cultural de determinadas classes sociais (BISSERET, 1974).

No contexto que nos interessa aqui, a tese na qual a meritocracia se apoia é, em princípio, simples: todos os cidadãos são, a rigor, iguais perante a lei e, portanto, adotar ações afirmativas voltadas à comunidade afrodescendente sugere, implicitamente, que, além de se instituir uma distorção no plano dos direitos universais, considera essa mesma comunidade inatamente incapaz, necessitando de ajuda para se "desenvolver", perpetuando assim o preconceito. Em resumo, a adoção 
de ações afirmativas, nesse sentido, subverteria o princípio do mérito, prejudicando o desenvolvimento do próprio país e provocando uma discriminação às avessas.

Respondendo à primeira parte dessa tese (aquela acerca do princípio do mérito) e deixando sua segunda parte (a suposta discriminação às avessas) para depois, quando trataremos de preconceitos que fundamentam alguns argumentos 'racistas" contra a política de cotas raciais, cumpre lembrar que o conceito de mérito depende, sobretudo, do critério utilizado para aferir determinado reconhecimento meritório. Via de regra, trata-se de critérios relativos, quando não inadequados, e, por isso mesmo, injustos. Um exemplo "clássico" é o dos famigerados vestibulares, utilizados para "regulamentar' o ingresso no ensino superior, regulamentação baseada fundamentalmente no "mérito" do ingressante.

A questão torna-se ainda mais complicada quando pensamos na realidade das sociedades complexas (como são as sociedades ocidentais modernas) e multiculturais (como são as contemporâneas), já que o conceito de mérito, neste contexto, não satisfaz as infinitas variações que essas sociedades apresentam. É o que afirma, por exemplo, Stuart Hall, ao refletir sobre a ideia de igualdade de mérito, quando lembra que tanto a liberdade individual quanto a igualdade formal são 'inadequadas à complexidade de vínculo, pertencimento e identidade introduzidas pela sociedade multicultural"; e que "profundas injustiças, exclusões sociais e desigualdades continuam a ser perpetradas em seu [da igualdade de mérito] nome" (HALL, 2003, p. 88).

Há que se lembrar, ainda, que a concepção neoliberal das relações sociais assenta-se sobre o postulado da meritocracia, exatamente pelo potencial individualista que esse conceito congrega em si: o mérito, tal como é entendido hoje em dia, é sempre causa e efeito de uma ação individual, um ato substantivamente isolado no complexo concerto das relações sociais. O ponto fraco da teoria da meritocracia, contudo, encontra-se exatamente no fato de partir de uma falsa premissa, a de que ele reflete diferenças reais instituídas em situações de concorrência igualitária. Ora, já no princípio da concorrência que se institui, a distância entre o 
capital sociocultural de seus componentes/concorrentes sugere diferenças que resultam, antes, de situações desiguais. É justamente esse modelo, que parte do "diferente" para se chegar ao "igual", o responsável por perpetuar as distorções que estão na base da teoria da meritocracia, cuja natureza individualista projeta, na sociedade, seu potencial discriminatório e excludente. Na verdade, o que se tem nesse modelo é justamente o inverso do que ele prega e sugere: uma concorrência desigual, que se institui a partir de diferenças construídas socialmente.

Reduzida ao universo da educação, essa é uma realidade que se vincula, como quer István Mészáros, diretamente à lógica reprodutiva do capital, que, em nome da suposta superioridade da elite, a que se convencionou qualificar de meritocrática, "exclui a esmagadora maioria da humanidade do âmbito da ação como sujeitos, e condena-os, para sempre, a serem apenas considerados como objetos (e manipulados no mesmo sentido)" (MÉSZÁROS, 2008, p. 49).

Não é somente o conceito - equivocado - de meritocracia que determina o ingresso na universidade, pois esse ingresso é balizado também pelo conceito de competitividade. Assim, enquanto a meritocracia diz respeito a um suposto saber disciplinar (caberia discutir, em outra oportunidade, de que lugar esse saber se afirma como tal, por quem e como ele é socialmente legitimado), a competitividade diz respeito a um saber paradisciplinar. Trocando em miúdos, para ingressar na universidade, o estudante afrodescendente necessita provar o domínio incondicional de uma razão epistemológica academicamente instituída e legitimada, a que, em geral, não teve acesso (o que coloca por terra o conceito de mérito), além de saber mobilizar uma sociabilidade da qual se encontra aprioristicamente alijado (invalidando, nesse sentido, o conceito de competição).

As cotas raciais vêm exatamente desarticular e desconstruir essa lógica perversa de exclusão, substituindo os conceitos de meritocracia e de competitividade por outros modelos e protocolos de inclusão do alunado afrodescendente no meio acadêmico. Isso pode ser feito, de maneira muito simples, apenas se invertendo a ordem dos fatores que 
determinam a acessibilidade ao ensino superior: ao invés de se promover uma suposta igualdade de ingresso na ponta final do processo seletivo do qual o vestibular é o exemplo mais saliente - , cumpre promover uma real igualdade de condições na ponta inicial desse processo - do qual o investimento no ensino fundamental de qualidade pode ser apontado como um dos fatores importantes. Nesse caso, em especial, a ordem dos fatores altera, substancialmente, o produto!

Cumpre responder, agora, à segunda parte do argumento que defende a meritocracia como fundamento das relações sociais nas sociedades complexas, aquela que sugere a ocorrência de uma suposta discriminação às avessas presente, in germine, na política de cotas raciais para ingresso no ensino superior.

O combate à ideologia da meritocracia — ideologia, aliás, muito próxima daquela que Marilena Chauí identificou em nosso meio universitário como sendo a ideologia da competência (CHAUÍ, 2014) - só tem sentido quando articulada ao combate contra preconceitos, que, muitas vezes, fundamentam argumentos racistas, os quais, assentados na defesa de uma justiça distributiva de natureza universal e essencialista, coloca-se contra a política de cotas raciais.

O primeiro desses argumentos preconceituosos é o que, no Brasil, os direitos são iguais para todos, portanto uma ação direcionada para determinado estrato da sociedade pode ser considerada uma discriminação às avessas. A adoção de ações afirmativas, nesse sentido, estaria ferindo o direito constitucional da igualdade, presente no Artigo $5^{\circ}$. de nossa Constituição.

Primeiramente, é necessário lembrar a distância que existe entre a igualdade formal e a concreta, pois, embora em nossa Constituição a igualdade de direitos esteja formalmente garantida, na prática ela não se concretiza plenamente. A igualdade, no sentido abstrato, pode possuir um sentido universalista inquestionável, mas, concretamente falando, significa também igualdade de oportunidades: por isso, na realidade, verifica-se que, embora todos tenham o direito à Educação, na prática, apenas alguns têm esse direito garantido. Nesse mesmo sentido, João Feres 
Júnior lembra-se da necessidade de nos conscientizarmos de que a ação afirmativa é uma política que busca, por meio da discriminação positiva, uma igualdade concreta e não formal: "quando e onde a igualdade formal da lei falha em produzir uma igualdade de fato, emprega-se a discriminação positiva" (FERES JÚNIOR, 2009, p. 42).

Nesse sentido, também Luciana Jaccoud e Mário Theodoro destacam os limites das políticas universalistas de combate ao racismo e à discriminação, sobretudo no contexto da Educação: embora aparentemente tais problemas possam ser solucionados com políticas educacionais de cunho universalista, o que se verifica, dizem os autores, é que as desigualdades verificadas no âmbito social também se reproduzem no educacional, como um alto índice de analfabetismo entre os negros; alta concentração da população negra no ensino fundamental, em oposição ao ensino superior; a enorme distorção, entre os negros, na relação idade-série; e o baixo desempenho escolar do alunado negro, mesmo neutralizando diferenças de nível socioeconômico. Enfim, no ponto de vista dos autores, para cada um desses fenômenos, é necessário interpor ações públicas igualmente distintas, já que enquanto a discriminação direta pode ser combatida por meio de um aparato legal, a indireta, mais dissimulada, só se torna visível por meio de indicadores de desigualdade étnico-racial; nesse caso, as ações de combate à discriminação indireta devem ser de dois tipos: as ações afirmativas e as ações valorativas (JACCOUD; THEODORO, 2005).

Argumentos dessa natureza são ainda complementados pela ideia de que, no Brasil, o "problema" que deve ser resolvido não é exatamente de natureza racial, mas de natureza social, pois a questão não seria de discriminação, mas de pobreza. Por isso, as soluções a serem adotas deveriam partir de uma perspectiva universalista, com medidas distributivas de caráter social. Ora, trata-se de uma típica visão maniqueísta da dinâmica social, desviando a discussão para um falso "problema": o de que a questão é social ou racial, quando na verdade há, entre nós, duas questões a serem resolvidas em instâncias distintas: uma racial $e$ outra social, embora, em geral, ambas estejam inter-relacionadas. É que, com 
frequência, o problema racial é subsumido pelo social; a questão torna-se mais evidente ao nos darmos conta de que, no Brasil, como se costuma dizer, pobreza tem cor: quanto mais preto, mais pobre, e vice-versa. Além disso, preconceito racial, que se traduz, na prática, em discriminações de fato, é reproduzido em cadeia no âmbito nas classes sociais, fazendo com que mesmo entre as classes mais pobres elas persistam.

A questão da discriminação racial nas instituições de ensino não está disseminada apenas nos três níveis pedagógicos que as conformam (fundamental, médio e superior), mas também nos três âmbitos fundamentais que compõem sua estrutura, o que torna a própria discriminação cuja gênese vincula-se a determinadas conjunturas históricas - num problema estrutural, quando então se corre o risco de se passar da discriminação para o racismo. No âmbito da gestão administrativa, a discriminação se reflete numa cadeia que nasce no modo muitas vezes autoritário como a escola é gerida, em que a instância dos colegiados é subjugada pelo poder centralizador do corpo gestor. No âmbito pedagógico, a discriminação se traduz numa prática pedagógica adotada no ambiente escolar, incidindo sobre vetores distintos da dinâmica ensino-aprendizagem, como o currículo e a avaliação; aqui, aliás, reside um dos espaços mais sensíveis à disseminação de atitudes discriminadoras que, por exemplo, podem se manifestar tanto nos instrumentos de avaliação quanto nos recursos didáticos. No âmbito político-social, a discriminação se desdobra em atitudes que se situam na interface escola-sociedade, tornando-se, talvez, o ambiente mais propício a atitudes discriminatórias. Avaliar a questão da discriminação na escola, essa autêntica categoria-gênese do racismo, torna-se, assim, um exercício que se legitima na consideração desses três âmbitos, atitude que adquire sentido maior ao se apoiar numa teoria que, em última instância, rege uma prática antidiscriminatória.

No que compete especificamente à universidade, objeto principal deste artigo, buscamos apontar o quanto uma educação plena, democrática nos seus conceitos e procedimentos, pública e popular, isto é, de todos e para todos, esbarra em preconceitos e exclusões que, não raras vezes, tem seu fulcro em práticas discriminatórias de natureza étnico-racial. 
Como afirma Boaventura de Sousa Santos, "na maioria dos países os fatores de discriminação, sejam eles a classe, a raça, sexo ou etnia, continuaram a fazer do acesso [à universidade] uma mistura de mérito e privilégio" (SANTOS, 2010, p. 67).

\section{Considerações finais}

Duas questões, à guisa de conclusão, podem ser levantadas no sentido de tornar a discussão mais densa, mas também de auxiliar na conscientização e erradicação da discriminação racial no Brasil, em particular no contexto da educação e do ensino superior: a importância de uma intervenção docente que se volte à educação para as relações étnico-raciais e à conscientização/reconhecimento das diferenças entre as discriminações de classe e de natureza étnico-racial.

Sobre a primeira, cumpre ressaltar a importância da intervenção docente no sentido de romper com as estruturas discricionárias e preconceituosas historicamente forjadas no ambiente escolar, seja no ensino fundamental, médio ou universitário. Talvez seja útil aplicar aqui o conceito de consciência possível, de extração hegeliana-marxista, mas adaptado por Lucien Goldmann ao plano da comunicação e da transmissão de informações na modernidade, justamente como método de intervenção na sociedade. Segundo o sociólogo e pensador franco-romeno, retomando a discussão acerca do conceito de consciência possivel (Zugerechnetes Bewusstsein), é essencial para aquele que quer intervir na sociedade saber quais são, numa dada situação, as informações que se podem transmitir, quais as que são transmitidas com modificações e quais não conseguem ser transmitidas. Nesse sentido e resumidamente, Goldmann propõe quatro abordagens (instrumentos de análise) do problema: primeiro, uma informação pode não ser transmitida por falta de informação prévia; segundo, considerando que - como mostra Freud - o inconsciente pode ser impermeável a certas informações, torna-se necessário, para que uma informação seja passada, operar uma transformação na consciência, num 
plano psicológico; terceiro, uma informação pode não ser veiculada pela resistência, de natureza social, de determinados grupos em relação às sua veiculação, uma espécie de recusa em aceitar determinadas ideias; a quarta, e mais importante, diz respeito àquela situação em que determinado grupo, para obter a transmissão de informações, precisa transformar-se, a ponto de perder suas características essenciais, já que há certas informações que são incompatíveis com as características fundamentais do grupo, por ultrapassarem o máximo de consciência possível do grupo. Relacionada à ideia hegeliano-marxista da passagem da quantidade para a qualidade, essa última abordagem refere-se à necessidade de "enquadrar o objeto estudado de modo a que possamos estudá-lo como desestruturação de uma estrutura tradicional e como nascimento de uma estrutura nova", chegando-se à conclusão de que "as transformações no interior de uma estrutura são tais que a estrutura antiga desaparece e em que uma estrutura nova acaba de nascer orientando-se em seguida para um novo estado de equilíbrio" (GOLDMANN, 1976, p. 22).

No que compete à intervenção docente, tal como a estamos propondo aqui, é exatamente esse o contexto em que se deve pensar: dialeticamente falando, as informações só poderão ser plenamente transmitidas e assimiladas por um determinado grupo com a desestruturação de uma estrutura tradicional e com o nascimento de uma estrutura nova, como exposto por Goldmann. Passando da teoria à prática e exemplificando dentro do contexto assinalado, uma vez inseridas as informações relativas ao universo cultural afro-brasileiro na escola (e na universidade) - como, inclusive, preveem recentes marcos normativos voltados para a questão das relações étnico-raciais na educação, a exemplo da lei 10639/03 —, as estruturas - reais ou imaginárias, mas sobretudo simbólicas — devem ser rompidas, paulatinamente, para dar lugar a outras estruturas novas, destituídas de vícios e ideias preconcebidas: o resultado certamente será, entre outras coisas, a construção de uma identidade afrodescendente "orgulhosa de si” ou a assunção, igualmente "orgulhosa de si”, de traços fenotípicos específicos. Por outro lado, a ruptura dessas mesmas estruturas reais ou imaginárias (por exemplo, por meio das ações afirmativas) contribuirá, como 
sugere mais uma vez Goldmann, para uma efetiva transmissão de informações para o grupo diretamente interessado nelas.

Aí se tem, portanto, a dinâmica da intervenção docente de que aqui se falou: ao mesmo tempo em que as informações relacionadas ao contexto afro-brasileiro são responsáveis pela ruptura da estrutura tradicional de determinados grupos (como, por exemplo, os "formadores de opinião"), outrora refratários a essas mesmas informações, essa ruptura viabiliza a transmissão dessas mesmas informações, alcançando-se uma síntese que se equaciona, a um só tempo, na quebra do preconceito étnico-racial e na assunção de uma nova identidade, agora assentada na cultura e nos valores afrodescendentes.

Sobre a segunda questão, a necessidade de conscientização/ reconhecimento das diferenças entre discriminações de classe e de natureza étnico-racial, no contexto assinalado, cumpre lembrar que nos parece equivocado querer combater as ações afirmativas usando como argumento a necessidade de expansão dessas ações à totalidade da população carente, sobrepondo - de modo astuto - uma realidade social a uma evidência étnico-racial. As ações afirmativas, tal como estão postas, têm como objetivo corrigir, pelo recurso da discriminação positiva, uma situação de natureza estritamente étnico-racial (o preconceito e a discriminação, por exemplo) que tem repercussões diversas na condição social do cidadão afrodescendente. O percurso, portanto, é do étnico-racial para o social, e não o contrário. Querer inverter essa equação, impondo uma trajetória que parte do social para, eventualmente, se alcançar o racial é desconsiderar que o racismo está presente, de modo crônico na sociedade, como um conceito supraclassista, interferindo em praticamente todas as suas instâncias. Sobrepor a questão da classe social à questão racial é, de certo modo, reativar a tese determinista, segundo a qual, nas palavras de Lília Schwarcz (1996), o indivíduo seria a soma dos caracteres rácico-culturais de seu grupo, sendo, nesse caso, melhor do que observar o indivíduo, observar o grupo a que ele pertence. Por isso, a questão das cotas, tal como nós a estamos apresentando aqui, diz respeito fundamentalmente à reparação e/ou compensação de práticas discriminatórias e excludentes 
de natureza étnico-racial. Não se pode negar, contudo, que, especialmente no contexto brasileiro, ela se completa com uma realidade que é basicamente de natureza social ou, para sermos mais precisos, de classe social. E isso tem um motivo claro: é que, entre nós, a mesma falácia que se encontra na gênese da ideia de democracia racial pode ser verificada na de democracia social, que resulta justamente do modo como, por aqui, as relações de classe se configuraram historicamente, com consequências que persistem ainda hoje de forma patente ou latente. Assim, um dos aspectos mais relevantes e peculiares dessa configuração é o de que, entre nós, as relações de classes apresentam uma ambiguidade congênita: enquanto que do ponto de vista dos relacionamentos sociais - isto é, de uma sociabilidade mais superficial, que prevê relações interclasses epidérmicas — a sociedade brasileira apresenta uma flagrante permeabilidade, do ponto de vista das relações sociais - ou seja, dos contatos mais profundos entre as classes, vinculados, por exemplo, à (im)possibilidade de mobilidade social —, nossa sociedade revela-se, ao contrário, altamente impermeável, o que se traduz de maneiras diversas: da exclusão à discriminação, da vitimização ao racismo, da precarização econômica ao alijamento político.

A questão racial não é redutível à questão de classe e nem deve ser por ela subsumida. Mas esses e outros fenômenos, acima apontados, mais ou menos simbólicos e com repercussões diretas na vida social das pessoas, revelam o quanto a questão de classe - e, especialmente, da divisão de classes - no Brasil continua presente, tornando o problema da discriminação racial ainda mais violento e dramático para a população afrodescendente.

\section{Referências}

BISSERET, N. Les inégaux ou la sélection universitaire. Paris, Presses Universitaires de France, 1974.

CHAUI, M. A ideologia da competência. São Paulo, Fundação Perseu Abramo/ Autêntica, 2014 (Escritos de Marilena Cahui, 3). 
FERES JÚNIOR, J. A política pública entre os movimentos sociais e a opinião douta. In: SILVÉRIO, Valter Roberto; MOEHLECKE, Sabrina (Orgs.). Ações afirmativas nas políticas educacionais. O contexto pós-Durban. São Carlos, EdUFSCar, 2009. p. 35-51.

GOLDMANN, L. A Criação Cultural na Sociedade Moderna. Para uma Sociologia da Totalidade. Lisboa, Presença, 1976.

GOMES, J. B. Barbosa. A recepção do instituto de ação afirmativa pelo direito constitucional brasileiro. In: SANTOS, S. A. Ações Afirmativas e combate ao racismo nas Américas. Brasília, SECAD/UNESCO, 2005. p. 47-82.

GONÇALVES, L. A. O. Negros e educação no Brasil. In: LOPES, Eliane Marta Teixeira; FILHO, Luciano Mendes Faria; VEIGA, C. G. (Orgs.). 500 anos de educação no Brasil. Belo Horizonte, Autêntica, 2003. p. 325-346.

HALL, S. Da diáspora. Identidades e mediações culturais. Belo Horizonte/Brasília, UFMG/UNESCO, 2003.

JACCOUD, L.; THEODORO, M. Raça e educação: os limites das políticas universalistas. In: SANTOS, Sales Augusto dos. Ações Afirmativas e combate ao racismo nas Américas. Brasília, SECAD/UNESCO, 2005. p. 105-120.

MÉSZÁROS, I. A educação para além do capital. São Paulo, Boitempo, 2008.

MINISTÉRIO DA EDUCAÇÃO / FUNDAÇÃO CULTURAL PALMARES. Cotas Raciais. Disponível em: <http://www.palmares.gov.br/?page_id=121>. Acessado em: jan. 2012.

SANTOS, B. S. A universidade no século XXI: para uma reforma democrática e emancipação da Universidade. São Paulo, Cortez, 2010.

SANTOS, R. E. Racialidade e novas formas de ação social: o pré-vestibular para negros e carentes. In: SANTOS, R. E.; LOBATO, F. (Org.). Ações afirmativas políticas públicas contra as desigualdades raciais. Rio de Janeiro, DP\&A, 2003. p. 127-153. 
SCHWARCZ, L. M. As teorias raciais, uma construção histórica de finais do século XIX. O contexto brasileiro. In: SCHWARCZ, L. M.; QUEIROZ, R. S. (Orgs.). Raça e diversidade. São Paulo, Edusp, 1996. p. 147-185.

Recebido: 22/04/17

Received: 04/22/2017

Aprovado: 02/06/17 Approved: 06/02/2017 
